\title{
The Motivational Profiles and Perceptions of Schooling of Asian Students in Australia
}

\section{DENNIS M MCINERNEY}

University of Western Sydney

\begin{abstract}
Asian-background students are performing better than other groups within the Australian educational setting. In order to investigate the reasons for this achievement advantage, this study examines the motivational profiles of Asianbackground and Anglo-background students in New South Wales Australia. The research utilises personal investment theory and self-concept theory to provide a research framework. 283 Asian-background and 887 Anglo-background students were administered the Inventory of School Motivation, the General Achievement Goal Orientation Survey, the Facilitating Conditions Survey, and the Academic Self Description Questionnaire.W hile the motivational and self-concept profiles of the two groups were surprisingly similar, there are core significant differences that help explain the Asian students' achievement advantage. Asian-background students are bighly task oriented and significantly more effort oriented, more competitive, praise and token oriented than the Anglo-background students. They have a significantly stronger sense of purpose for schooling and are moreperformance oriented. Asian-background students also have a stronger intention to go on to university and further study, value school and like school more than their Anglo peers. These results are consistent with those reported in earlier studies with Asian American students.
\end{abstract}

\section{INTRODUCTION}

At an aggregate level, young people from non-English speaking backgrounds (NESB) have higher post-compulsory education participation rates than Australian born and English-speaking background (ESB) migrant groups (Marginson, 2004; Marks, Fleming, Long \& McMillan, 2000; Williams, Long, Carpenter \& Hayden, 1993). Students from non-English-speaking backgrounds are more likely to enroll in high status school subjects or courses, such as mathematics, the physical sciences, economics, business, and languages other than English (Ainley \& Perry, 1994; Sturman, Sharpley \& Polesel, 1992; Ainley 
Jones \& Navaratnam, 1990). Moreover, it is found that students from NES background have a more positive view of their schooling experience (Sturman, 1997; Ainley, 1995; Ainley \& Perry, 1994) and that the academic aspirations of students and parents of students from NESB appear to be higher than for ESB students and parents (Meade, 1983).

However, studies have indicated that the apparent high rate of participation in higher education is not in itself a true indication of the success of all minority NESB students in schools and school performance of children frequently did not match their high aspirations or the high aspirations of parents (Teese, McLean, \& Polese, 1995). While NESB students, on average, have higher Year 12 (the final year of post compulsory schooling in Australia) retention rates, a larger proportion of them achieve low to medium Higher School Certificate scores in comparison to students whose parents are Australian born and for which English language proficiency appears to be a major determinant of achievement. Studies also indicate that there are variations within and between ethnic groups in educational achievement; some minority groups achieve better than others (Marks, Fleming, Long \& McMillan, 2000).

Sturman (1997) argues that one of the major limitations of reviews of research into the educational experiences of immigrant Australians is that most research combines immigrant background students into very broad categories distinguishing between three broad groups: (a) Australian-born students, (b) students born overseas in nonEnglish-speaking countries, and (c) students born overseas in Englishspeaking countries. The problem with this type of categorization is that there can be variations and differences within a group that are sometimes greater than the differences between groups. For instance, within the group of students born in non-English-speaking countries, research indicates that there can be differences in parents' aspirations and students' achievement. There are also differences within groups of students who are born in Australia but whose parents come from non-English speaking countries. For example, while there are Asian students who have difficulty with English and do not satisfy their educational aspirations, there are Asian students who are academically highly successful (see, for example, in the United States context, Huang \& Waxman, 1996). 


\section{Asian students academic achievement in Australia}

It is commonly believed that Asian students, inclusive of students from China, Vietnam, Hong Kong, Cambodia, Phillipines, Japan and Thailand, are doing well within Australia's educational system in comparison to the mainstream group of Anglo Australians and a number of other non-English speaking background minority groups such as the Lebanese-background students (Marginson, 2004; Marks et al, 2000; Suliman \& McInerney, in press; see also Huang \& Waxman 1994; Eaton \& Dembo 1997 for an American comparison). Eaton and Dembo (1997) state in the United States' context that Asian American students have outperformed their non-Asian counterparts on many commonly accepted indices of educational achievement. This achievement pre-eminence might be a stereotypical representation of a generalised situation which ignores differences that exist between recent Asian arrivals and earlier arrivals, and Asians from different subgroups. Nevertheless, on an aggregate level, it does appear that Asian students achieve better at school than many comparator groups. This differential in achievement is puzzling because Asian students have English as a second language, are often recent arrivals, may have suffered trauma and interrupted schooling, and come from cultural backgrounds that may make learning in Western oriented schools problematic (see, for example, ERIC Development Team 1993; Siu, 1996). It is also puzzling that other minority students, such as Lebanese-background students, with similar demographic and cultural profiles are doing relatively poorly in Australian schools.

\section{What is known about the learning and motivational styles of Asian background students?}

Little is known about the learning and motivational characteristics of Asian students in the Australian setting, and in particular those characteristics that might be most related to their school success. There is, however, some literature available on the learning styles of Asian students in the United States and China (see, for example, Liu \& Littlewood, 1997; Park, 2000; Zhenhui, 2005). Stereotypically Asian students are believed to have a set of learning style characteristics derived from socialization practices within their homes and communities that may ill suit them for schooling in Western contexts such as in Australia. Typically Asian students are thought to benefit most from teacher centered and book centered approaches to learning with an emphasis on rote memory (Liu \& Littlewood, 1997). They are thought to be 
passive learners and prefer not to demonstrate their knowledge publicly. They are also thought to be intolerant of ambiguity in learning situations, to be less autonomous learners, to have high respect for authority, commitment to family traditions, strong social hierarchy, and male dominance, as well as strong reticence and humility (Park, 2000). Nevertheless, there is also evidence that suggests that some Asian students do not accept traditional values such as obedience, moderation, humility, and harmony, viewing them as dysfunctional in a modern society (Trueba, Cheng \& Ima, 1993). In any event, the salience of these 'traditional' characteristics varies across Asian groups depending on the cultural values they hold underpinned by ideologies such as Buddhism and Confucianism. Some of these traditional values, such as traditions of hard work (effort); deferring gratification, valuing education and respect for the teacher are also very compatible with white middle-class values espoused by most Western school systems. In any event, cultural values are not static and are likely to change as children are socialized into schooling in Western schools and perceive the opportunities or lack of opportunities that schooling is likely to present them with.

There is, in reality, little information available on Asian students' motivation, perceptions of their learning environments (including the influence of parents, peers and teachers), and how these relate to achievement outcomes (see, for example, Siu, 1996). Huang and Waxman (1996; see also 1994) examined a number of these factors relating to Mathematics education among resilient (students doing very well at school) and non-resilient (students not doing well at school) Asian American students with similar demographic backgrounds. The study found that resilient Asian American students were more confident of attending graduate school; they had higher school attendance, and spent more time on homework than their non-resilient peers. Both groups valued education highly and had high Achievement Motivation (the extent to which students felt the intrinsic desire to succeed and earn 'good' marks in mathematics) and Affiliation Motivation (the extent to which students know, help, and are friendly toward each other in their mathematics class). Resilient Asian American students were significantly higher on Academic Self-concept (the extent to which students self-report pride in their class work and expect to do well in mathematics) and Achievement Motivation. They also had greater Involvement (the extent to which students report active participation in their mathematics class), Satisfaction (the extent of students' self- 
report of enjoyment of their mathematics class work) and Affiliation (self-reported extent to which students know, help, and are friendly toward each other in their mathematics class). There was no significant difference in Parental Involvement (students' self report on how much parents are interested and involved in what their children are doing in mathematics) between the two groups. In summary, the research found that resilient Asian students were more affiliation oriented, had significantly greater intrinsic desire to succeed and earn good grades, and exhibited more pride in their class work than non-resilient students. However, there were no differences in perceived parental interest and support for the students' education.

In a comparison with Anglo-American students (Huang \& Waxman, 1994) Asian students were surer they would attend graduate schools, and had better attendance records. Asian students spent more time on their homework (effort). While both Anglo-American and Asian students had high scores on Affiliation (working with others on mathematics), Academic Self-concept and Achievement Motivation, Asian students were significantly higher on Academic Self-concept and Achievement Motivation than the Anglo American students. They also reported more Involvement, Satisfaction, and Parental Involvement, but significantly less Affiliation than the Anglo students. These results underlined the fact that Asian success at school might be related to their love of learning, deep determination to succeed, and family influences (Huang \& Waxman, 1994).

Eaton and Dembo (1997) suggested that the difference in academic achievement among Asian and non-Asian students in the United States may be related to their attributions to effort rather than ability and higher parental expectations that their children will succeed at school. Eaton and Dembo argue that as a consequence Asian students believe that their achievement can be attributable to internal controllable forces, namely, effort at their work, and that there is, therefore a greater fear among Asian students of failure at school because this will be dishonourable for their family. Hence, Asian students put more effort into their school work and spend less time watching television, socialising and engaging in sport and recreational activities than their non-Asian peers leading to, on average, higher school achievement. As a consequence of family dynamics they value schooling more than their non-Asian peers.

As indicated above little is known about the motivational profiles of Australian Asian students. This study sought to examine a complex 
set of variables based on Personal Investment Theory PI (Maehr \& Braskamp, 1986) and Self-concept theory (see, for example, Marsh \& Craven, 1997) that might distinguish between Asian and AngloAustralian students in the school setting.

\section{Personal Investment Theory}

Personal Investment Theory PI (Maehr \& Braskamp, 1986, see also Maehr \& McInerney, 2004) is concerned with how persons choose to invest their energy, talent, and time in particular activities. PI theory is particularly relevant in investigations into how individuals of varying social and cultural backgrounds relate to differing achievement situations such as schooling. This is because the theory does not assume that people from a given culture or group will invest effort in the same achievement situations or, if they do, for the same reasons, as those from other cultures and groups. PI theory also emphasizes the role played by social and cultural contexts in determining motivational patterns in performing achievement tasks. Moreover, it is phenomenologically based, and emphasises the subjective meaning of situations in light of individuals' culturally determined belief systems such as beliefs about self, perceptions of appropriate goals, and perceived alternatives available for pursuing these goals.

PI theory is a social-cognitive theory, as it assumes that the primary antecedents of choice, persistence and variations in activity levels are thoughts, perceptions and beliefs that are embedded in cultural and social beliefs about self and situation. Specifically, PI theory designates three basic components of meaning as critical to determining personal investment in specific situations:

- beliefs about self, referring to the more or less organized collections of perceptions, beliefs, and feelings related to who one is.

- perceived goals of behaviour in given situations, referring to the motivational focus of activity, importantly what the person defines as 'success' and 'failure' in this situation. Among these goals are Task, Ego, Social Solidarity, and Extrinsic Rewards.

- perceived alternatives or facilitating conditions for pursuing these goals, referring to the behavioural alternatives that a person perceives to be available and appropriate (in terms of sociocultural norms and opportunities that exist for the individual) in a given situation. 
Each of these components of PI theory may be influenced differentially by the structure of tasks and situations, personal experience and access to information and, importantly, the sociocultural context in which tasks, situations, and persons are embedded.

PI theory predated goal theory but incorporated within its framework three elements that were to become increasingly the major focus of motivational research in educational settings, namely, mastery (task) goals, ego (performance) goals, and social goals. However, while much goal theory research over the last twenty years has concentrated on comparing and contrasting the effects on behaviour of mastery and performance with a much more recent and somewhat belated attempt to broaden goals to include social goals, PI not only was a multiple goal oriented theory from its inception, but also included sense of self and facilitating conditions dimensions that made it, potentially, a far richer and more sensitive source of information on the motivational determinants of behaviour. Particularly this was the case in socioculturally diverse settings.

\section{Self-Concept}

It is also widely accepted that an individual's self concept is related to school adjustment, satisfaction and achievement (Marsh, 1990, 1992, 1993; Marsh \& Craven, 1997; see also Graham, 1994).). It is widely accepted that academic achievement is more strongly related to academic self-concept than to non-academic and general components of self-concept. In general, research indicates that specific academic self concepts, such as Mathematics and Verbal are strongly positively correlated to their respective academic achievements, but are nearly uncorrelated with each other. In contrast, academic achievement in various areas is moderately to highly correlated (Marsh, 1992). In order to examine the nature and importance of self concept to the Asian and Anglo Australian students participating in this study, three academic self-concept scales, drawn from Marsh's ASDQ (Marsh, 1992) were included, viz, English Self Concept, Maths Self-Concept and General Academic Self-Concept. To these scales were added four other Sense of Self scales namely, Positive and Negative Self Esteem, Self Reliance and Sense of Purpose drawn from the Inventory of School Motivation (see McInerney, Roche, McInerney \& Marsh, 1997, and Maehr \& Braskamp, 1986) to examine whether academic self-concept measures taken from the ASDQ related more strongly to achievement than these more general measures. 


\section{Outcome measures}

Three objective achievement outcome measures were included in the study, namely, Mathematics Rank and English Rank, taken from the mid-year assessments at each school, and days absent in Term Two of the year the study was conducted. Three self report measures drawn from the FCQ were also included as outcome measures for some analyses, namely, Intention for University, School Valuing and Affect for School.

\section{Purpose of the study}

There is a dearth of information on the motivational profiles of Asian students studying in Australian schools and how these profiles relate to their school achievement. Utilising Personal Investment Theory and Self-concept theory, this research compares motivational profiles of a sample of Asian background students studying in mainstream high schools in New South Wales Australia with the motivational profiles of Anglo-Australian students at the same schools. It relates these profiles to a range of important educational outcomes, and compares and contrasts the profiles and important predictors for the two groups. The research compares these motivational profiles with extant research on the motivation and learning of Asian students.

\section{METHOD}

\section{Participants}

Subsamples of 1170 participants of a larger study (2917 participants) were surveyed. These included 887 Anglo Australian students ( $M=456$, $\mathrm{F}=429)$ and 283 students from Asian background ( $\mathrm{M}=118, \mathrm{~F}=152)$. The Asian students comprised the following subgroups Vietnamese (42\%), Chinese (25\%), Cambodian (16\%), VietChinese (6\%), and others (11\%). $31 \%$ of the students were born in Australia, 33\% in Vietnam, $12 \%$ in Cambodia and 6\% in China. The remaining students (18\%) were born in a range of other countries. $40 \%$ of the students spoke Vietnamese at home, $21 \%$ of the students spoke Chinese, $15 \%$ spoke Cambodian, 16\% spoke English, and 8\% spoke a range of other languages at home. Virtually all the fathers and mothers of the students were born overseas, so the students are the first generation of their families going to school in Australia. Students were drawn from grades $7(\mathrm{~N}=420), 8(\mathrm{~N}=397)$ and $9(\mathrm{~N}=348)$ from eleven urban and rural 
high schools in New South Wales Australia, broadly typical of mainstream high schools. The average age of the students was 13 years.

\section{Instruments}

Four instruments were used in this study: (a) the Inventory of School Motivation (ISM), (b) the Facilitating Conditions Questionnaire (FCQ), (c) the General Goal Orientation Scale (GAGOS), and (d) the Academic Self-description Questionnaire (ASDQ). Each of these instruments has been used in cross cultural research and each has strong psychometric properties (see, for example, Barker, McInerney \& Dowson, 2004; Dowson, Barker \& McInerney 2004; McInerney \& Ali, in press, 2006; McInerney, Marsh \& Yeung, 2003; McInerney, Yeung \& Dowson, 2005; McInerney, Yeung \& McInerney, 2001; Watkins, McInerney \& Boholst, 2003; Yeung \& McInerney, 2000). Cronbach alphas are presented at the end of each scale based on analyses with the full sample size of 3120 students.

The Inventory of School Motivation. The Inventory of School Motivation (ISM) consists of 43 items comprising eight motivational scales. Extensive cross-cultural validation analyses using CFA and invariance testing demonstrate the validity and reliability of these scales for use in cross-cultural settings. These background analyses will not be reported here and the reader is encouraged to read McInerney and Ali (in press). Reliability tests conducted on the scales indicated good reliability. Samples of items in each of the scales are given below:

Task: (4 items) Measures the student's interest in the task of learning and wanting to improve understanding. Examples of this dimension are "I like to see that I am improving in my schoolwork" and "I try harder with interesting schoolwork". (á=.66)

Effort: (7 items) Measures the willingness of students to expend effort to improve schoolwork. Examples of this dimension are "When I am improving in my schoolwork I try even harder" and "I am always trying to do better in my schoolwork". (á=.81)

Competition: (6 items) Measures a student's competitiveness in learning. Examples of this dimension are "I like to compete with others at school" and "I work harder if I am trying to be better than others". $(\mathbf{a}=.75)$

Social Power: (6 items) Measures the degree to which seeking social power and status through school work is important to a student. Examples of this dimension are "I work hard at school to be put in 
charge of a group" and "I work hard at school because I want the class notice me". (á=.80)

Affiliation: (3 items) Measures the student's interest in belonging to a group when doing schoolwork. Examples of the dimension are "I can do my best work at school when I work with others" and "I prefer to work with other people at school rather than work alone". $(\mathbf{a}=.68)$

Social Concern: (5 items) Measures the student's concern for other students and a willingness to help them with their school work. Examples of this dimension are "It is very important for students to help each other at school" and "I like to help other students do well at school". (á=.70)

Praise: (5 items) Measures the degree to which praise and recognition for schoolwork is important to a student. Examples of this dimension are "At school I work best when I am praised" and "I want to be praised for my good schoolwork". (á=.80)

Token: (7) Measures the degree to which tangible rewards for schoolwork are important to a student. Examples of this dimension are "I work best in class when I get some kind of rewards" and "I work hard in school for rewards from the teacher". (á=.79).

The Inventory also measures four Sense of Self scales which refer to the more or less organised collections of perceptions, beliefs, and feelings related to who one is in the school context:

Sense of purpose: (6 items) Measures the degree to which a student values school for the future. Examples of this dimension are "I aim my schooling towards getting a good job" and "I want to do well at school to have a good future". (á=.82)

Self reliance: (8 items) Measures a student's self-reliance and confidence within academic settings. Examples of this dimension are "I often try new things on my own" and "I don't need anyone to tell me to work hard at school". (á=.69)

Negative Self-esteem: ( 7 items) Measures a student's negative feelings about their general academic ability at school. Examples of this dimension are "I often worry that I am not very good at school" and "I often think that there are things I can't do at school". (á=.66)

Positive Self-esteem: (5 items) Measures a student's positive feelings about their general academic ability at school. Examples of this 
dimension are "I succeed at whatever I do at school" and "I think I'm as good as everybody else at school”. (á=.72)

Facilitating Conditions Questionnaire. The Facilitating Conditions Questionnaire consists of 55 questions about eight background variables clustered around parent, peer and teacher influences that are believed to facilitate or inhibit the performance of students at school.

Positive parent support (6 items) Measures a student's perception of positive parental support. Examples of this dimension are "My mother helps me with my schoolwork". (á=.86)

Negative parent support (5 items) Measures a student's perception of negative parental support. Examples of this dimension are "My father doesn't pay any attention when I bring home report cards". $(\mathbf{a}=.81)$

Parental pride (4 items) Measures the importance to a student of parental pride in their school achievements. Examples of this dimension are "It's important for my father to be proud of my schoolwork". $(\mathbf{a}=.82)$

Positive teacher support (6 items) Measures a student's perception of positive teacher support. Examples of this dimension are "My teachers help me with my schoolwork". (á=.80)

Positive peer support (5 items) Measures a student's perception of positive peer support. Examples of this dimension are "My friends help me with my schoolwork". (á=.81)

Negative peer support (4 items) Measures a student's perception of negative peer support. Examples of this dimension are "Some of my friends tell me I should leave school when I can”. (á=.72)

Positive peer valuing of school (4 items) Measures the degree a student perceives their peers value school. Examples of this dimension are "Most of my friends want to do well at school". (á=.70)

Leaving school (4 items) Measures a student's perception of influences on leaving school. Examples of this dimension are "My mother doesn't mind if I leave school when I want to". (á=.85)

Intention to complete university (5 items) Measures a student's intention to complete further education. Examples of this dimension are "I intend to go on to college or university". (á=.92)

Valuing schooling (9 items) Measures the degree a student values education. Examples of this dimension are "Education is important for me to get a job" (á=.87) 
Positive affect to school (3 items) Measures the degree to which a student appears to like school. Examples of this dimension are "like studying”. (á=.75)

General motivation scales. The General Achievement Goal Orientation Scale (GAGOS) (see Yeung \& McInerney, 2000) consists of five general motivation scales:

Valuing motivation (3 items) Measures how much a student values motivation at school. Examples of this dimension are: "Motivation is important to do well at school" and "Students who are motivated do well at school". (á=.68)

Global motivation (5 items) Measures a student's perception of how motivated they are at school. Examples of this dimension are: "I feel motivated at school a lot of the time" and "I am often motivated in my schoolwork". (á=.82)

Mastery general (5 items) Measures a student's perception of how mastery oriented they are. Examples of this dimension are: "I am most motivated when I see my work improving" and "I am most motivated when I am becoming better at my work". (á=.75)

Performance general ( 7 items) Measures a student's perception of how performance oriented they are. Examples of this dimension are: "I am most motivated when I am doing better than others" and "I am most motivated when I receive good marks". (á=.82)

Social general (4 items) Measures a student's perception of how socially oriented they are. Examples of this dimension are: "I am most motivated when I work with others" and "I am most motivated when I am in a group". $(a ́=.74)$

Academic Self-description Questionnaire. Academic self-concepts are concerned with how students see their abilities generally, and specifically in terms of English and Mathematics. Items were selected from Marsh's ASDQ (1992) instrument namely:

General Academic Self-concept (5 items) Self-conceptions regarding student's overall abilities. Examples of this dimension are "I get good marks in most school subjects" and "I learn things quickly in most school subjects". 
English Self-concept (5 items) Students self-conceptions of their English abilities. Examples of this dimension are "I am good at English" and "Work in English is easy for me".

Mathematics Self-concept (5 items) Students self-conceptions of their Mathematics abilities. Examples of this dimension are "I have always done well in Mathematics" and "I learn things quickly in Mathematics".

Students responded to the items in each instrument on a fivepoint Likert scale ranging from strongly disagree (1) to strongly agree (5).

\section{Dependent variables}

Six dependent variables were used in the analyses to examine the relative strength of the predictor variables in explaining school achievement of Asian and Anglo Australian students. These dependent variables were three self-report measures drawn from the FCQ: Desire to complete University, Affect to school, Valuing of school, and three objective measures: mathematic achievement, English achievement, and attendance at school. The three objective dependent variables used in the study. were based on achievement ranks in the students' mid year tests in these subjects, and attendance at school was based on school records of student absences in the term prior to the study.

As well as collecting information about the motivational goals of students, the survey also sought information on sociocultural and demographic profiles of participants including sex, age, place of birth of students and parents, language spoken at home, parental occupation, level of education of parents, religion and cultural traditions practiced by students.

\section{Statistical analyses}

For purposes of this research descriptives on all variables were computed. MANOVA analyses were used to examine differences between the two groups (Anglo-Australian and Asian), and multiple regression analyses were used to examine the relationships between the independent variables and dependent variables. 


\section{RESULTS AND DISCUSSION}

Table 1 presents the descriptive statistics and results of the MANOVA comparing the Asian and Anglo-Australian students. Each instrument was considered in a single block.

Table 1. Descriptive Statistics and Significance Differences (MANOVA, wilks lambda) on Scales and outcome Measures for Australian and Asian groups

\begin{tabular}{|c|c|c|c|c|c|c|c|}
\hline \multirow[t]{2}{*}{ Scales } & \multicolumn{2}{|c|}{ Australian } & \multicolumn{2}{|c|}{ Asian } & \multicolumn{3}{|c|}{ MANOVA } \\
\hline & Mean & SD & Mean & SD & F ratio & df, edf & Sign \\
\hline ISM & & & & & 20.035 & 8,1155 & 0.000 \\
\hline Task & 4.27 & 0.54 & 4.27 & 0.62 & 0.000 & 1 & 0.987 \\
\hline Effort & 4.00 & 0.64 & 4.28 & 0.57 & 43.875 & 1 & 0.000 \\
\hline Competition & 2.97 & 0.85 & 3.47 & 0.86 & 75.206 & 1 & 0.000 \\
\hline Social Power & 2.62 & 0.82 & 2.90 & 0.89 & 22.465 & 1 & 0.000 \\
\hline Affiliation & 3.72 & 0.90 & 3.68 & 0.80 & 0.436 & 1 & 0.509 \\
\hline Social Concern & 3.71 & 0.66 & 3.86 & 0.61 & 9.610 & 1 & 0.002 \\
\hline Praise & 3.47 & 0.86 & 3.72 & 0.82 & 18.600 & 1 & 0.000 \\
\hline Token & 3.01 & 0.84 & 3.47 & 0.87 & 61.781 & 1 & 0.000 \\
\hline Sense of Self & & & & & 6.435 & 4,1159 & 0.000 \\
\hline Sense of Purpose & 4.31 & 0.59 & 4.44 & 0.56 & 10.257 & 1 & 0.001 \\
\hline Sense of Reliance & 3.84 & 0.52 & 3.79 & 0.52 & 2.444 & 1 & 0.118 \\
\hline Negative Self Esteem & 2.77 & 0.68 & 2.73 & 0.57 & 0.540 & 1 & 0.463 \\
\hline Positive Self Esteem & 3.71 & 0.71 & 3.70 & 0.70 & 0.103 & 1 & 0.749 \\
\hline GAGOS & & & & & 10.178 & 5,1155 & 0.000 \\
\hline Mastery General & 3.99 & 0.62 & 4.01 & 0.59 & 0.140 & 1 & 0.708 \\
\hline Performance General & 3.12 & 0.78 & 3.34 & 0.67 & 19.076 & 1 & 0.000 \\
\hline Social General & 3.50 & 0.78 & 3.60 & 0.66 & 3.273 & 1 & 0.071 \\
\hline Motivation Value & 4.13 & 0.67 & 4.01 & 0.68 & 7.165 & 1 & 0.008 \\
\hline Global Motivation & 3.47 & 0.80 & 3.65 & 0.65 & 12.063 & 1 & 0.001 \\
\hline FCQ & & & & & 27.586 & 11,1147 & 0.000 \\
\hline Unint & 3.58 & 0.87 & 3.81 & 0.71 & 15.283 & 1 & 0.000 \\
\hline Svalue & 4.33 & 0.59 & 4.46 & 0.55 & 10.243 & 1 & 0.001 \\
\hline Psupp & 3.66 & 0.82 & 3.41 & 0.96 & 18.381 & 1 & 0.000 \\
\hline Tsupp & 3.71 & 0.74 & 3.90 & 0.65 & 15.361 & 1 & 0.000 \\
\hline Phelp & 3.36 & 0.84 & 3.60 & 0.74 & 17.688 & 1 & 0.000 \\
\hline Lschl & 1.89 & 0.89 & 1.73 & 0.88 & 7.766 & 1 & 0.005 \\
\hline Prdoth & 3.74 & 0.82 & 4.03 & 0.74 & 27.468 & 1 & 0.000 \\
\hline Nprnt & 1.66 & 0.72 & 1.84 & 0.88 & 11.368 & 1 & 0.001 \\
\hline Afsch & 3.12 & 0.92 & 3.87 & 0.88 & 142.346 & 1 & 0.000 \\
\hline Npeer & 2.57 & 0.84 & 2.33 & 0.79 & 19.145 & 1 & 0.000 \\
\hline Ppeer & 3.85 & 0.63 & 4.06 & 0.60 & 24.410 & 1 & 0.000 \\
\hline
\end{tabular}




\begin{tabular}{lccccccc}
\hline ASDQ & & & & & $\mathbf{8 . 9 6 8}$ & $\mathbf{3 , 1 1 4 1}$ & $\mathbf{0 . 0 0 0}$ \\
English & 3.48 & 0.82 & 3.30 & 0.78 & 11.037 & 1 & 0.001 \\
Mathematics & 3.32 & 1.00 & 3.51 & 0.86 & 7.252 & 1 & 0.007 \\
General & 3.67 & 0.75 & 3.53 & 0.70 & 6.900 & 1 & 0.009 \\
\hline Criterion Variable & & & & & $\mathbf{9 . 3 5 3}$ & $\mathbf{3 , 7 0 1}$ & $\mathbf{0 . 0 0 0}$ \\
Math Rank & 3.09 & 0.95 & 3.40 & 0.89 & 14.650 & 1 & 0.000 \\
English Rank & 3.20 & 0.92 & 3.21 & 0.74 & 0.016 & 1 & 0.899 \\
Attendance of School & 1.38 & 0.73 & 1.17 & 0.64 & 11.735 & 1 & 0.001 \\
\hline
\end{tabular}

Note: Unint = Intention to complete university; Svalue = Valuing schooling; Psupp = Positive parent support; Tsupp = Positive teacher support; Phelp = Positive peer help; Lschl = Leaving school; Prdoth = Pride from others; Nprnt $=$ Negative parental support; Afsch $=$ Positive affect to school; Npeer $=$ Negative peer support; Ppeer $=$ Positive peer support; $\mathrm{SD}=$ Standard Deviation; edf $=$ error df.

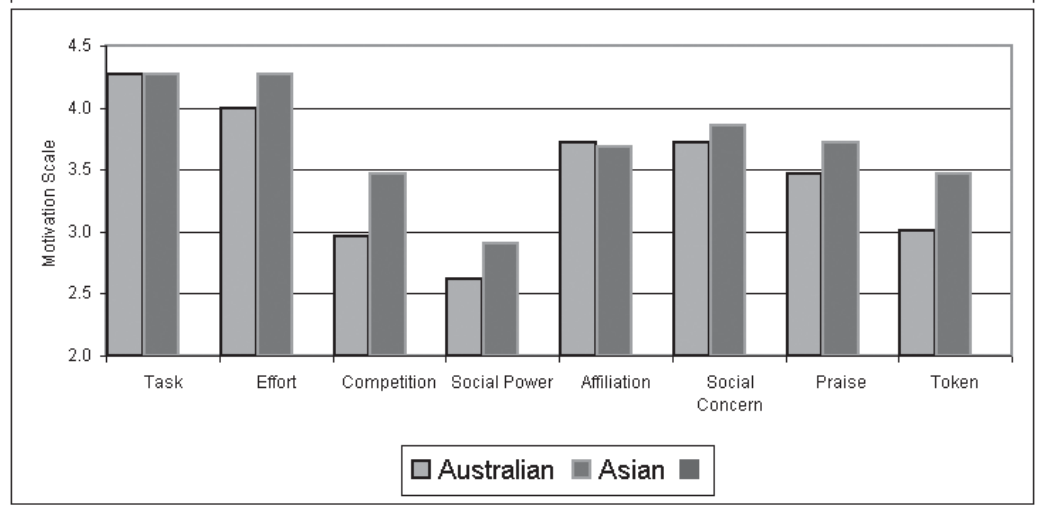

Figure 1. Motivation Profile by Cultural Groups

Inventory of School Motivation. Both Asian and Anglo-Australian students are strongly task and effort oriented $(>4)$ with the Asian students being significantly more effort oriented that the Anglo Australian students. Both groups are moderately strong on affiliation, social concern and praise $(>3)$ with the Asian background group being significantly stronger on social concern and praise. Neither group strongly endorse competition $(<3.5)$ and social power $(<3.0)$. The Asian background group is significantly stronger on competition and social power than the Anglo-Australian group, although social power is not endorsed by either group. The Asian background group is more strongly token 
oriented than the Anglo-Australian group. While there are a number of significant differences between the two groups the patterns of endorsement of each of the motivators are very similar. The two striking differences are the Asian group's significantly stronger endorsement of competition and token reinforcement as motivators.

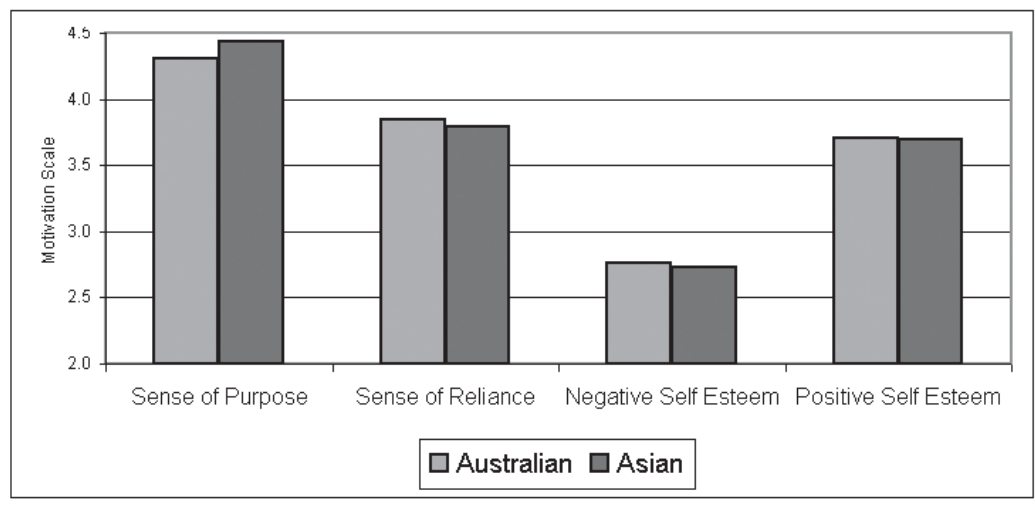

Figure 2. Self of Sense Scale by Cultural Groups

Sense of Self. Both Asian background and Anglo-Australian groups have a strong sense of purpose for their schooling $(>4)$ and a strong sense of reliance (>3.5), however, the Asian background group was significantly stronger on sense of purpose. Both groups have low negative self esteem $(<3)$ and relatively high positive self esteem $(>3.5)$ within the school setting with no significant differences between the two groups on these variables.

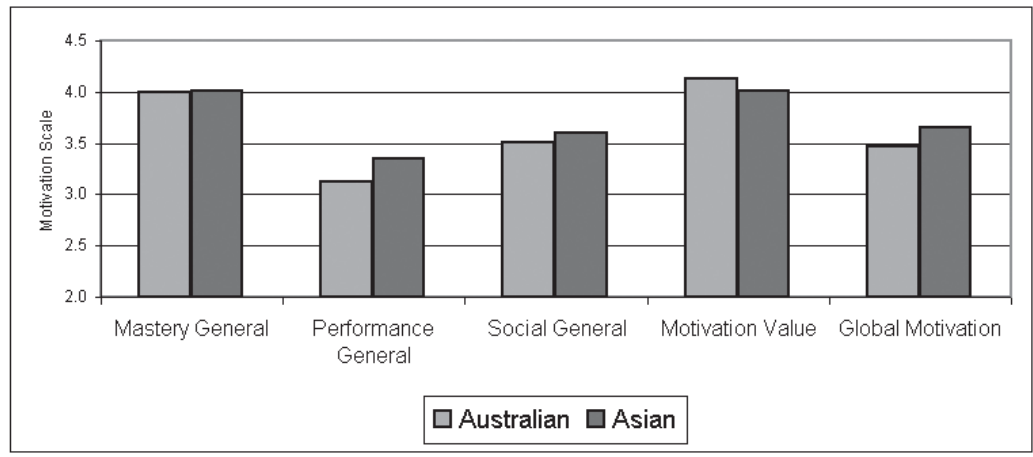

Figure 3. General Achievemet Goal Orientation by Cultural Groups 
General Achievement Goal Orientation Scale. Both groups are strongly mastery oriented (4) with no significant difference between the groups. Neither group was strongly performance oriented $(<3.5)$ however, the Asian background group was significantly more performance oriented than the Anglo-Australian group. Both groups were moderately socially oriented (e"3.5) with no significant difference between the two groups. Both groups were moderate on global motivation (e"3.5) but Asian background students were significantly stronger on global motivation. While both groups strongly endorsed the value of being motivated at school (e"4) Anglo-Australian students were significantly stronger on this variable. In summary, irrespective of the significant differences the pattern of motivators was remarkably similar across the two groups.

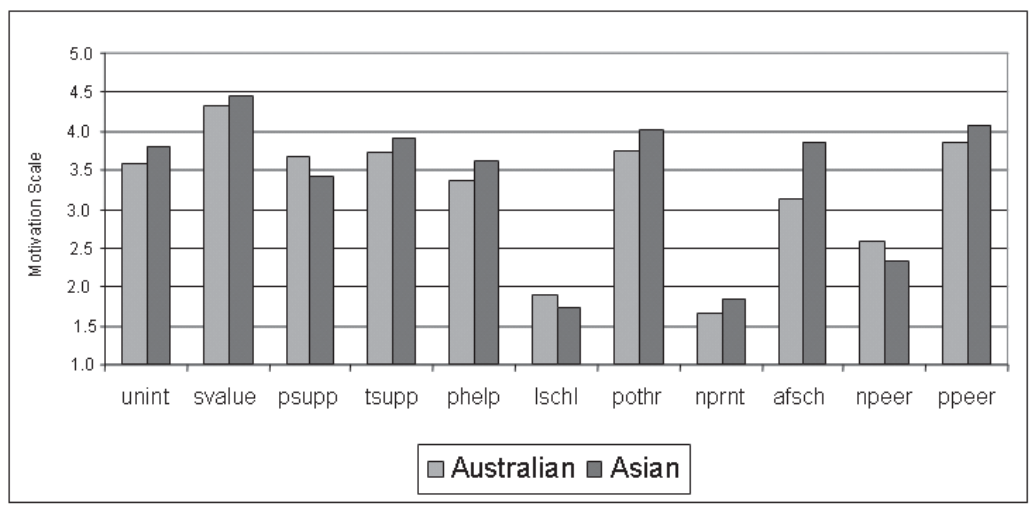

Figure 4. Facilitating Condition Questionnaire by Cultural Groups

Facilitating Conditions Questionnaire. There were significant differences across the Facilitating Conditions scales, although in most instances the differences were minor. Both groups moderately endorsed the value of going on to University (>3.5) with the Asian background group significantly stronger on this. Both groups strongly valued schooling ( $>4$ ) with the Asian background group being significantly stronger. Both groups moderately endorsed the importance of positive parent support $(>3)$ with the Anglo Australian group significantly stronger on this dimension. Both groups endorsed the importance of teacher and peer support and help (>3), with the Asian background group significantly stronger on these dimensions. Both groups were low on leaving school $(<2)$, negative parent support $(<2)$ and negative peer support $(<3)$ with the Asian background group significantly lower 
on both leaving school and negative peer influence, while the AngloAustralian group was significantly lower on negative parent support. The Asian background group was significantly stronger on affect to school. Again, patterns of endorsement of the various facilitating conditions were similar across the two groups. However, the major distinguishing features appear to be the Asian background group's stronger endorsement of intention to go on to University, positive peer help, parental pride, and affect to school, and the Anglo-Australian group's stronger endorsement of parent support and negative peer support.

Academic Self Description Questionnaire. There was moderate endorsement of the three ASDQ scales by both groups $(>3)$. There were, however, significant differences across the three academic selfconcepts. The Asian background students were significantly stronger in their mathematics self-concept while the Anglo-Australian students were significantly stronger in their English self-concept. The AngloAustralian students were significantly stronger in their general academic self-concept. Despite these significant differences the actual margin of difference between the two groups was quite small as illustrated in Figure 5.

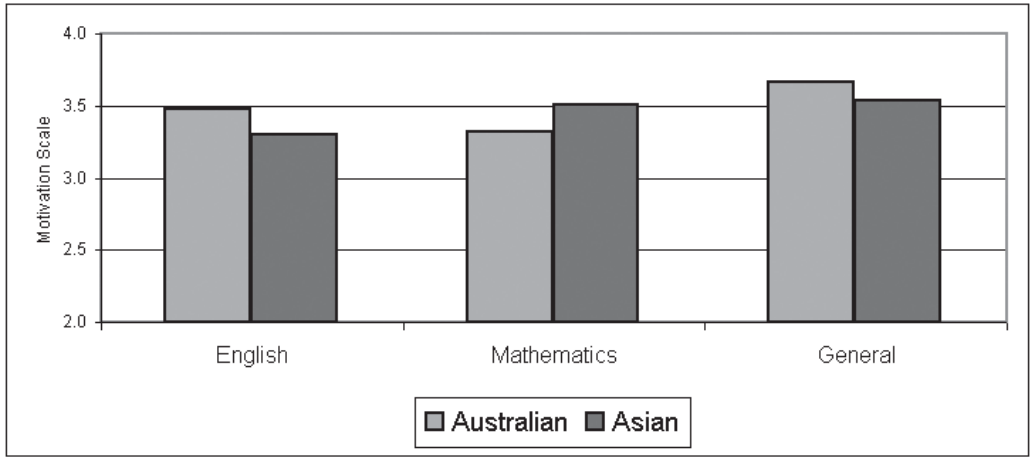

Figure 5. Self Concept Scales by Cultural Groups

\section{What are the significant predictors of school achievement?It} appears from the objective outcome measures used that the Asian background students in this sample are doing better at mathematics, and miss less days of schooling than their Anglo-Australian peers. This is in line with previously reported research conducted in the United States. They are also performing equally well in English despite having non-English speaking language backgrounds. The Asian background 
students also more strongly endorse going onto university after school, and like and value school more than their Anglo peers, which is also in line with previously reported research.

In order to ascertain whether there were differences in patterns of prediction of the various motivational and self-concept scales used in this study a series of multiple regression analyses were conducted. Table 2 presents the results of the regression analyses using the three self-report outcome measures taken from the Facilitating Conditions Questionnaire regressed on the ISM, Sense of Self, GAGOS, and ASDQ scales. A quick glance at the table indicates that across three outcome measures a significant amount of variance was explained for the two groups, ranging from $10 \%$ to $53 \%$. Scales from the FCQ were not used in these regression analyses because of the intercorrelation between these scales and the self-report outcome measures Affect, Intention to complete University, and Valuing education.

\section{Outcome variables}

Three objective outcome variables were used in this study, mathematics rank, English rank and attendance at school (number of days absence in the term preceding the conduct of the survey). The mathematics rank of the Asian background students was significantly higher than the Anglo-Australian students, and they missed significantly less school than the Anglo students. There was no significant difference on English rank.

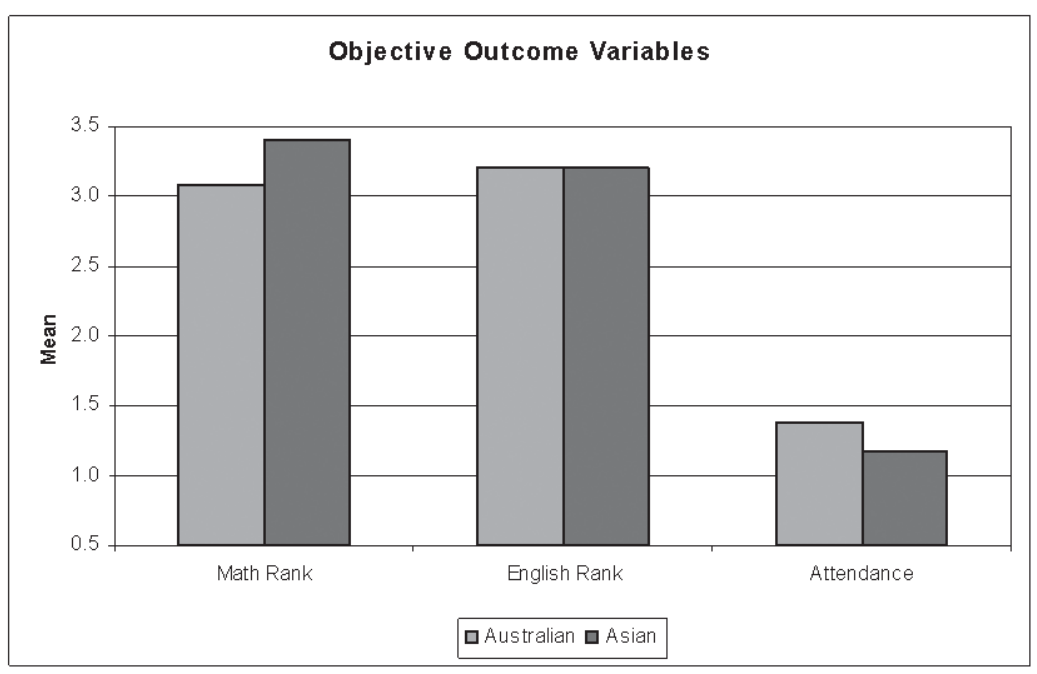

Figure 6. Objective Outcome Variables 
Inventory of School Motivation. The eight ISM scales were able to explain a reasonable level of variance in the three outcome measures ranging from $18 \%$ to $39 \%$. Of the eight ISM variables effort was a strong and consistent predictor for the three outcomes for the two groups. Task was also a consistent and strong predictor for the Asian background group. Competition was a strong predictor for both groups on valuing education. Social power was a consistent significant predictor of the three outcomes for the Asian background group (negative predictor for valuing education). Social power was less important for the Anglo-Australian group. Interestingly, token reinforcement was a significant negative predictor for further education for both groups. In summary, the strongest predictor across the three outcomes was consistently effort motivation for both groups. As reported above, the Asian background group was significantly stronger on effort than the Anglo Australian group.

Sense of Self. These four scales were able to explain a high level of variance in the three self report outcome measures ranging from $24 \%$ to $53 \%$. Clearly sense of purpose was the strongest predictor for each group across each of the three outcome measures. All four measures were significantly related to intention for university for each group with negative self-esteem being a negative predictor. Sense of reliance was relatively more important to the Asian background group. Positive and negative self-esteem appear more important to the Asian background group in predicting affect to school, while sense of reliance appears more important to the Anglo-Australian group. In summary, however, the predominant predictor for each of the outcome measures for both groups is sense of purpose. As reported above the Asian background was significantly stronger on sense of purpose than the Anglo-Australian group.

General Achievement Goal Orientation Scale. These five scales were able to explain a reasonable level of variance in the three outcome measures ranging from $14 \%$ to $34 \%$. The predominant predictor for each group on each outcome measure was mastery general, except for affect for the Asian background group for which global motivation was the predominant predictor. As reported above there was no significant difference between the two groups on mastery motivation. However, the Asian background group was significantly stronger on global motivation.

Academic Self Description Questionnaire. The three ASDQ scales explained from $10 \%$ to $35 \%$ of variance across the three scales. The 
predominant predictor for each group across the three outcome measures was general academic self-concept. While English self-concept and mathematics self-concept were predictors for the Anglo-Australian group for each of the three outcome measures this was not the case for the Asian background group. These three variables were related to intention to go on to university, but not to valuing school nor English for affect for the Asian background group. The dominant message from this analysis indicates that level of general academic self-concept strongly predicts intention to complete further education, how much students value school, and how much they like school for both Asian and Anglo background students. As indicated earlier the Anglo-Australian students are significantly stronger on general academic self-concept than the Asian background students, although the difference is slight.

\section{Summary}

A clear message emerges from these analyses using self-report outcome variables. The most salient predictors are consistent for the Asian and Anglo-Australian groups these being: Effort, Sense of Purpose, Mastery General/Global Motivation, and General Academic Self-concept. Asian background students are significantly stronger on three of these variables: effort, sense of purpose, and global motivation.

\section{Mathematics, English and School Attendance}

Three objective outcome measures were also utilised in this study, namely, mathematics ranks, English ranks and number of days absent from school. It is not expected that the same level of variance will be explained in the multiple regression analyses using these outcomes as there are many variables associated with these outcomes that may have little to do with a student's motivation or self-concept. Nevertheless, these analyses give some promising evidence of the likely salient predictors of school achievement. A glance at Table 3 illustrates that across the three outcome variables a small but significant amount of variance was explained in many cases. 
Table 2. Model summary and standardized coefficients (Beta) of multiple regressions across Australian and Asian groups on valued academic outcomes

\begin{tabular}{|c|c|c|c|c|c|c|}
\hline \multirow[t]{2}{*}{ SCALES } & \multicolumn{2}{|c|}{ Furthed } & \multicolumn{2}{|c|}{ Value } & \multicolumn{2}{|r|}{ Affect } \\
\hline & Australian & Asian & Australian & Asian & Australian & n Asian \\
\hline ISM & $\mathrm{R}^{2}=0.18 *$ & $\mathrm{R}^{2}=0.29 *$ & $\mathrm{R}^{2}=0.32^{*}$ & $\mathrm{R}^{2}=0.39 *$ & $* \mathrm{R}^{2}=0.36 *$ & $\mathbf{R}^{2}=0.37 *$ \\
\hline Task & .037 & $.275^{*}$ & $.162^{*}$ & $.309 *$ & -.046 & $-.138 *$ \\
\hline Effort & $.287^{*}$ & $.299 *$ & $.345^{*}$ & $.306^{*}$ & $.500^{*}$ & $.562 *$ \\
\hline Competition & $.035-$ & .095 & $.207 *$ & $.177 *$ & -.016 & -.043 \\
\hline Social Power & .054 & $.198^{*}$ & $-.085^{*}$ & $-.136^{*}$ & $.111 *$ & $.238^{*}$ \\
\hline Affiliation & $-.099 *$ & -.104 & $.080 *$ & .006 & $-.158^{*}$ & -.095 \\
\hline Social Concern & $.118^{*}$ & .099 & .002 & -.015 & $.104 *$ & $.131 *$ \\
\hline Praise & .081 & .035 & $.095^{*}$ & .098 & $.092 *$ & -.024 \\
\hline Token & $-.150 *$ & $-.184 *$ & -.066 & -.081 & -.067 & .026 \\
\hline Sense of Self & $\mathrm{R}^{2}=0.24^{*}$ & $\mathrm{R}^{2}=0.33^{*}$ & $\mathrm{R}^{2}=0.46^{*}$ & $\mathrm{R}^{2}=0.53^{*}$ & $\mathbf{R}^{2}=0.27 *$ & $\mathrm{R}^{2}=0.25^{*}$ \\
\hline Sense of Purpose & $.306^{*}$ & $.309^{*}$ & $.607^{*}$ & $.668^{*}$ & $.249 *$ & $.225^{*}$ \\
\hline Sense of Reliance & $.086^{*}$ & $.179 *$ & .021 & .092 & $.267^{*}$ & .040 \\
\hline Negative SE & $-.135^{*}$ & $-.152^{*}$ & .018 & $-.113^{*}$ & $-.104 *$ & $-.177 *$ \\
\hline Positive SE & $.108^{*}$ & $.141 *$ & $.110^{*}$ & -.030 & .033 & $.244^{*}$ \\
\hline GAGOS & $\mathrm{R}^{2}=0.14 *$ & $\mathrm{R}^{2}=0.23^{*}$ & $\mathrm{R}^{2}=0.27 *$ & $\mathbf{R}^{2}=0.34 *$ & $\mathrm{R}^{2}=0.29 *$ & $\mathrm{R}^{2}=0.25^{*}$ \\
\hline Mastery Gl & $.119 *$ & $.284^{*}$ & $.312^{*}$ & $.421 *$ & $.096^{*}$ & -.059 \\
\hline Performance Gl & -.022 & .062 & $.093 *$ & .086 & .044 & $.119 *$ \\
\hline Social Gl & -.053 & -.055 & .008 & .000 & $-.074 *$ & -.028 \\
\hline Motivation Value & $.078 *$ & $.182 *$ & $.154^{*}$ & $.267^{*}$ & -.005 & -.011 \\
\hline Global Motivation & $.257^{*}$ & .099 & $.083^{*}$ & -.082 & $.480^{*}$ & $.494 *$ \\
\hline ASDQ & $\mathrm{R}^{2}=0.19 *$ & $\mathrm{R}^{2}=0.35 *$ & $\mathrm{R}^{2}=0.15 * \mathrm{R}$ & ${ }^{2}=0.16 *$ & $\mathrm{R}^{2}=0.20 * \mathrm{~F}$ & $\mathrm{R}^{2}=0.10^{*}$ \\
\hline English & $.130^{*}$ & $.140^{*}$ & $.137 *$ & .045 & $.180^{*}$ & .101 \\
\hline Mathematics & $.169 *$ & $.149 *$ & $.138^{*}$ & .037 & $.125^{*}$ & $.140^{*}$ \\
\hline Gl Academic & $.251^{*}$ & $.426^{*}$ & $.224 *$ & $.351 *$ & $.253^{*}$ & $.160^{*}$ \\
\hline
\end{tabular}

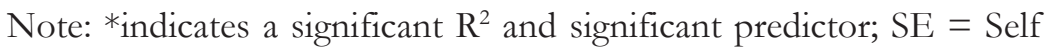
Esteem; Gl = General 
Table 3. Model summary and standardized coefficients (Beta) of multiple regressions across Australian and Asian groups on criterion variables.

\begin{tabular}{|c|c|c|c|c|c|c|}
\hline \multirow[t]{2}{*}{ SCALES } & \multicolumn{2}{|c|}{ Math Rank } & \multicolumn{2}{|c|}{ English Rank } & \multicolumn{2}{|c|}{ Attendance } \\
\hline & Australian & Asian & Australian & Asian & Australian & Asian \\
\hline ISM & $\mathrm{R}^{2}=0.05^{*}$ & $R^{2}=0.16^{*}$ & $\mathrm{R}^{2}=0.07 * \mathrm{R}$ & $\mathbf{R}^{2}=0.07 *$ & $\mathbf{R}^{2}=0.02 * \mathbf{R}$ & $2^{2}=0.04$ \\
\hline Task & -.058 & .131 & .040 & .026 & -.010 & .076 \\
\hline Effort & $.126 *$ & .106 & $.121 *$ & $.226^{*}$ & -.090 & -.100 \\
\hline Competition & .055 & $.199 *$ & .001 & -.032 & .049 & -.059 \\
\hline Social Power & -.063 & $-.276^{*}$ & -.025 & -.159 & -.035 & -.089 \\
\hline Affiliation & $-.160^{*}$ & $-.143 *$ & $-.117 *$ & -.120 & $.095^{*}$ & .093 \\
\hline Social Concern & .057 & .041 & .080 & .033 & -.016 & -.095 \\
\hline Praise & .035 & -.177 & .031 & -.081 & .021 & -.010 \\
\hline Token & -.077 & -.034 & $-.126^{*}$ & .010 & -.062 & .009 \\
\hline Sense of Self & $\mathrm{R}^{2}=0.10 *$ & $\mathrm{R}^{2}=0.11 *$ & $\mathrm{R}^{2}=0.09 * \mathrm{R}$ & $\mathrm{R}^{2}=0.03 \mathrm{R}$ & $\mathrm{R}^{2}=0.02 * \mathrm{R}^{2}=$ & $=0.07 *$ \\
\hline Sense of Purpose & .015 & .063 & $.104 *$ & .025 & -.033 & -.052 \\
\hline Sense of Reliance & $.132 *$ & .092 & .056 & .007 & .038 & $-.292 *$ \\
\hline Negative SE & $-.264 *$ & $-.310^{*}$ & $-.262^{*}$ & -.122 & $.106^{*}$ & .016 \\
\hline Positive SE & -.037 & -.102 & -.060 & .100 & -.063 & $.187 *$ \\
\hline GAGOS & $\mathbf{R}^{2}=0.04 *$ & $R^{2}=0.13 *$ & ${ }^{k} \mathbf{R}^{2}=0.05 * 1$ & $\mathbf{R}^{2}=0.07 *$ & $\mathbf{R}^{2}=0.01 \mathbf{R}^{2}$ & $=0.11 *$ \\
\hline Mastery Gl & -.004 & $.235^{*}$ & -.015 & $.219^{*}$ & -.089 & $-.297 *$ \\
\hline Performance Gl & .028 & $-.170^{*}$ & .011 & -.114 & -.044 & -.067 \\
\hline Social Gl & $-.182^{*}$ & $-.233^{*}$ & $-.119 *$ & $-.175^{*}$ & .073 & .083 \\
\hline Motivation Value & .035 & $.159 *$ & $.184^{*}$ & .009 & .047 & $.218^{*}$ \\
\hline Global Motivation & $.126^{*}$ & -.067 & .083 & -.064 & -.031 & -.094 \\
\hline FCQ & $\mathrm{R}^{2}=0.11 *$ & $\mathrm{R}^{2}=0.23 *$ & $\mathrm{R}^{2}=0.13 * \mathrm{R}$ & $\mathrm{R}^{2}=0.11 * \mathrm{I}$ & $\mathrm{R}^{2}=0.02 \mathrm{R}^{2}=$ & $=0.09$ \\
\hline Unint & $.212^{*}$ & .107 & $.174 *$ & .141 & $-.110^{*}$ & -.060 \\
\hline Svalue & -.002 & .129 & .048 & .124 & .028 & .026 \\
\hline Psupp & .058 & -.081 & -.077 & .056 & -.012 & -.139 \\
\hline Tsupp & -.019 & .039 & .035 & -.006 & -.064 & -.020 \\
\hline Phelp & $-.126 *$ & -.076 & -.002 & -.045 & .029 & .163 \\
\hline Lschl & -.009 & -.024 & .032 & -.045 & -.053 & $.272 *$ \\
\hline Pothr & -.016 & $-.216^{*}$ & -.067 & $-.219 *$ & -.025 & -.012 \\
\hline Nprnt & -.070 & $-.198^{*}$ & $-.102 *$ & .010 & .070 & -.296 \\
\hline Afsch & .025 & .132 & .097 & .027 & .065 & -.012 \\
\hline Npeer & $-.128^{*}$ & $-.150^{*}$ & $-.185^{*}$ & $-.178^{*}$ & .029 & .082 \\
\hline Ppeer & $-.120^{*}$ & $-.172 *$ & $-.106^{*}$ & -.059 & -.027 & -.079 \\
\hline ASDQ & $\mathrm{R}^{2}=0.14 *$ & $\mathrm{R}^{2}=0.12 *$ & $\mathrm{R}^{2}=0.08 * \mathrm{R}$ & $\mathrm{R}^{2}=0.01 \mathrm{R}$ & $\mathrm{R}^{2}=0.01 \mathrm{R}^{2}=$ & $0.009 *$ \\
\hline English & .076 & .053 & $.245^{*}$ & .084 & .049 & -.011 \\
\hline Mathematics & $.379 *$ & $.370 *$ & .009 & -.057 & -.004 & -.041 \\
\hline General Academic & -.048 & -.138 & .065 & .061 & $-.118^{*}$ & -.061 \\
\hline
\end{tabular}

Note: *indicates a significant $\mathrm{R}^{2}$ and significant predictor; $\mathrm{SE}=$ Self Esteem; Gl = General. 
A quick summary of Table 3 illustrates some results that underline the importance of the salient variables described in Table 2. For example, effort is a strong predictor for English rank for both Asian background and Anglo-Australian students. It is also a significant predictor for mathematics rank for the Anglo-Australian students. Competition is a strong predictor for Asian background students mathematics rank, and social power is a strong negative predictor of mathematics rank. It's interesting to note that affiliation is a negative predictor for mathematics and English ranks and that there is no significant difference between the two groups on this variable.

Of the sense of self variables negative self esteem is consistently a strong negative predictor of mathematics for both groups and English ranks for the Anglo-Australian group. Negative self-esteem is also a positive predictor of days missed from school for the Anglo group, while sense of reliance is a strong negative predictor of days missed for the Asian background students. There is no significant difference between the two groups on negative self esteem, or on self reliance.

Of the GAGOS scales mastery general was a strong positive predictor of mathematics and English ranks for the Asian background group. It was also a strong negative predictor of days missed at school. Both groups were strong on mastery motivation. Social general was also a significant negative predictor of mathematics and English ranks for both groups while valuing motivation was a strong positive predictor of mathematics for the Asian background group. Valuing motivation was, inexplicably, also a positive predictor of days missed at school for the Asian background group. The Anglo-Australian group was significantly stronger on valuing motivation. Performance general was a significant negative predictor of mathematics for the Asian background group. In common with the Asian background students, social general was a negative predictor of mathematics and English ranks for the Anglo-Australian students. Global motivation was a significant predictor of mathematics rank, while valuing motivation was a significant predictor of English rank for the Anglo group.

The facilitating conditions scales were also utilised as predictors of mathematics, English and attendance. For mathematics and English these eleven scales were able to explain a reasonable amount of variance in the outcome measures ranging from $11 \%$ to $23 \%$. However the scales did not explain a significant level of variance in attendance for either group. Intention to go on to university was the strongest positive predictor of mathematics and English ranks for the Anglo-Australian group. Interestingly though, it was not a predictor for either outcome 
for the Asian group although the Asian background group was significantly stronger on this variable. Three other variables emerged as negative predictors for the Anglo-Australian group, namely, parent help, negative peer and positive peer for mathematics, and negative parent, negative peer and positive peer for English. The strongest predictor for the Asian background group was pride from others which was negatively related to both mathematics and English ranks. Negative peer influence was a strong negative predictor of both mathematics and English ranks for this group. Negative parent and positive peer were also negative predictors of mathematics ranks for the Asian background students. Earlier studies have indicated the importance of positive peer and parental relations for Asian school success.

Finally the ASDQ scales were able to explain a significant level of variance for mathematics ranks for the Asian background and Anglo-Australian students, and English ranks for the Anglo-Australian students. Mathematics self-concept was a strong positive predictor of mathematics ranks for both groups, while English self-concept was a strong positive predictor of English rank for the Anglo-Australian group. The Asian background group was significantly stronger on mathematics self-concept than the Anglo-Australian group, the AngloAustralian group was significantly stronger on English self-concept, and there was no significant difference on general academic self concept.

\section{Summary}

While the level of variance explained in these latter analyses was generally small there are some promising results with mathematics and English outcomes. Effort, affiliation, negative self-esteem, social general, negative peer and positive peer appear to be significant predictors for both groups. Otherwise, the results, such as the importance of competition, social power, mastery general and performance general, and mathematics self-concept for the Asian background group underlines and supports the analyses relating these variables to the self-report outcome variables.

\section{Success at school and Asian background students in Australia}

Utilising the Personal Investment model has allowed us to investigate a complex pattern of motivators, sense of self, and facilitating factors across two cultural groups. Probably the strongest finding to come from this research is the striking similarity between the motivational profiles of Asian background and Anglo-Australian background 


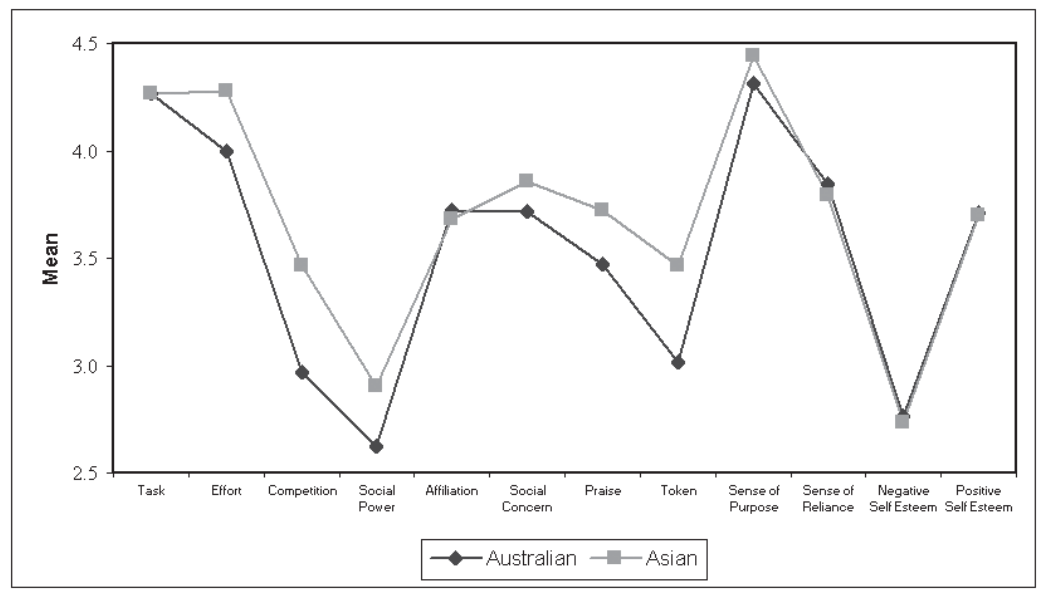

Figure 6. Motivation Profile by Cultural Groups

students as illustrated in Figures 6,7 and 8. How one group endorses a motivational, sense of self, or facilitating variable, the other group endorses in a similar manner. Nevertheless, the analyses provide us with some insights into why Asian background students do well within the Australian school system. They are highly task oriented and significantly more effort oriented, they are also significantly more

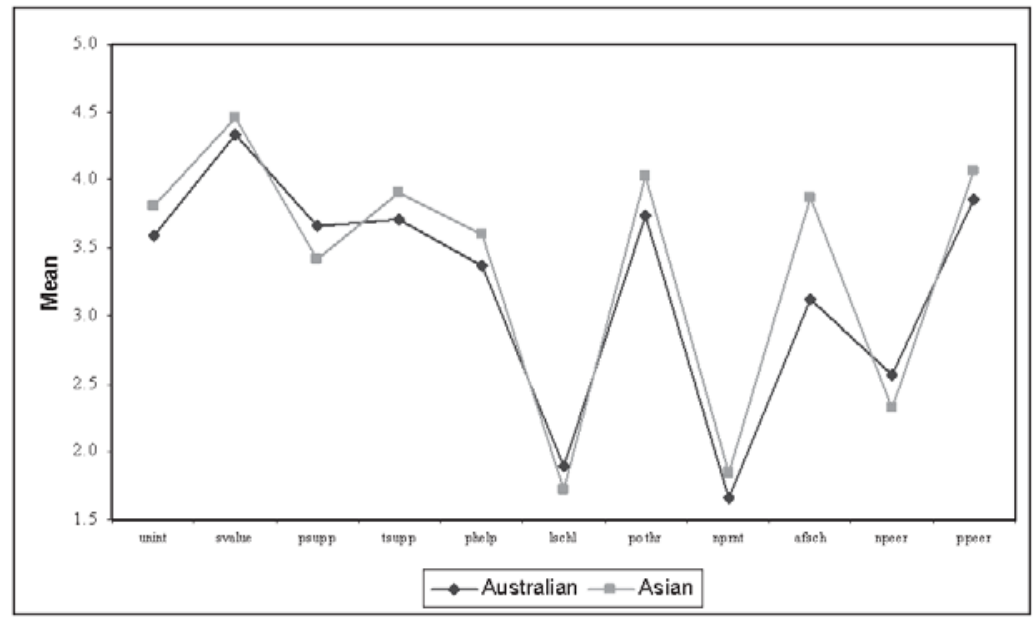

Figure 7. Facilitating Condition Questionnaire by Cultural Groups

competitive than the Anglo-Australian students and significantly more praise and token oriented. They have a significantly stronger sense of 
purpose for schooling and are more performance oriented. They have a stronger intention to go on to university and further study, value school and like school more than their Anglo peers. These results are consistent with those reported in earlier studies with Asian American students.

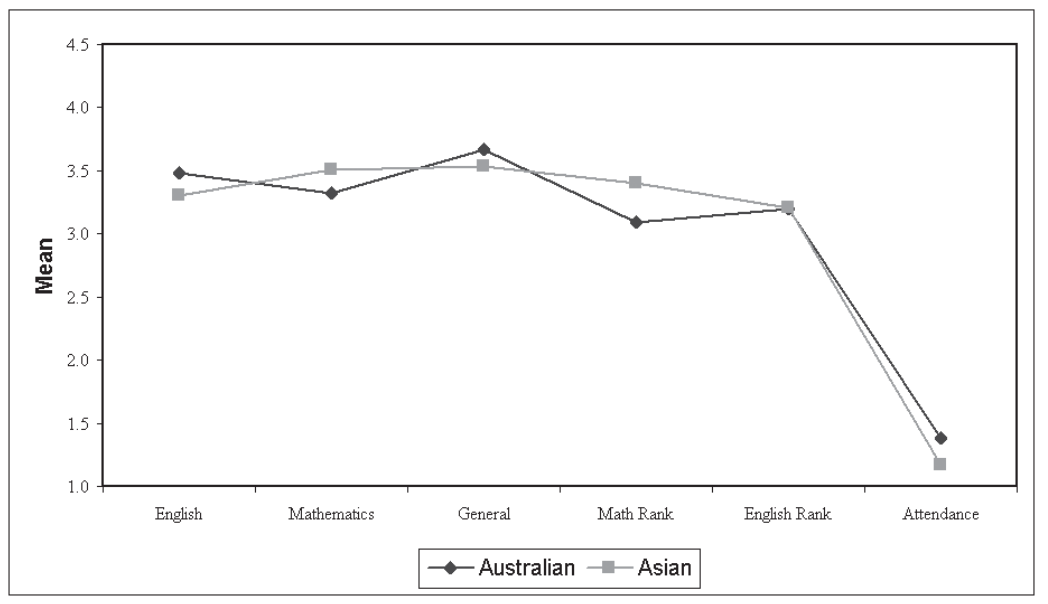

Figure 8. Self Concept and Outcomes by Cultural Groups

The pattern of results from the multiple regression analyses were not strong enough to make conclusive statements about the relationship of these variables to school achievement. A larger sample size and better achievement outcome criteria are required in order to estimate the relationship of these variables to achievement outcomes. It is also important to acknowledge that the Asian background group comprised a number of East and South East Asian groups each of which might have different motivational dynamics.

\section{Limitations}

This study included students from both South-east-Asian (Vietnamese and Cambodian) and East Asian (Chinese) backgrounds and it is possible that separate analyses of these groups would reveal within-group differences, differences based on the pre-immigration school experiences some students had prior to their arrival in Australia, and different cultural perspectives on education characteristic of the various groups. In order to examine this, follow-up studies with larger sample sizes are necessary. 
Among the Asian background students there are students who are doing well within the school system (resilient students), while others may be doing less well (non-resilient students). The motivational profiles of different achievement groups among the Asian background students need to be examined, as well as whether it is more or less likely that particular groups with Asian background (such as South-east Asian, or East Asian) are doing well at school. This issue also needs to be investigated with a larger sample of students.

\section{REFERENCES}

Ainley, J. (1995) Students' views of their schools. Unicorn, 21 (3), 5-16. Ainley, J. \& Perry, L. (1994) Students and their primary schools. In State of Queensland, Shaping the Future: Vol.2. (Report of the Review of the Queensland School Curriculum). Brisbane: State of Queensland.

Ainley, J., Jones, W. \& Navaratnam, K.K. (1990) Subject choice in senior secondary school (Report to DEET). Canberra: Australian Government Publishing Service.

Barker, K. L., McInerney, D. M. \& Dowson, M. (2004) Advances in the conceptual understanding of students' goals and academic self-concept. A multidimensional and hierarchical approach. In Proceedings Self-concept, motivation and identity: Where to from here? Third International Biennial SELF Research Conference, Berlin, Germany, 4-7 July, 2004.

Dowson, M., Barker, K., \& McInerney, D. M. (2004) The chicken or the egg? Exploring causal relations between motivational goals, self-concept, and academic achievement. Paper presented at the Annual Meeting of the American Educational Research Association, San Diego, USA.

Dowson, M., Barker, K., \& McInerney, D. M. (2004) Who's on first? Causal ordering of academic self-concept, motivational goals, and achievement. In Proceedings Self-concept, motivation and identity: Where to from here? Third International Biennial SELF Research Conference, Berlin, Germany, 4-7 July, 2004.

Eaton, M. J. \& Dembo, M. H. (1997) Differences in the motivation beliefs of Asian and Non-Asian students. Journal of Educational Psychology, 89, 433-440. 
ERIC Development Team (1993) ED366673 1993-12-00 Beyond culture: Communicating with Asian American children and families. ERIC/CUE Digest Number 94. ERIC.

Graham, S. (1994) Motivation in African Americans. Review of Educational Research, 64, 55-117.

Huang, S-y. L, \& Waxman, H. C. (1994) Differences in Asian-and Anglo-American students' motivation and learning environment in mathematics. Paper presented at the annual meeting of the American Educational Research Association, April, New Orleans.

Huang, S-y. L, \& Waxman, H. C. (1996) Comparing learning environment of resilient and non-resilient Asian American students. Paper presented at the Annual Meeting of the American Educational Research Association, April 8-12, New York.

Liu, N. F., \& Littlewood, W. (1997) Why do students appear reluctant to participate in classroom learning discourse? System, 25 (3), 371-384.

Maehr, M. L. \& Braskamp, L. A. (1986) The Motivation Factor: A Theory of Personal Investment. Lexington, MA: Lexington Press.

Maehr, M. L. \& McInerney, D. M. (2004) Motivation as personal investment. In D. M. McInerney \& S. Van Etten (eds.), Research on Sociocultural Influences on Motivation and Achievement. Vol. 4. Big Theories Revisited. Greenwich, CT: Information Age Publishing.

Marginson, S. (2004). They still call multiculturalism home: Migration, language and education in Australia. Multicultural Futures Conference, Monash University, Prato, 22-23 $3^{\text {rd }}$ September.

Marks, G. N., Fleming, N., Long, M. \& McMillan, J. (2000). Patterns of participation in Year 12 and Higher Education in Australia: Trends and Issues. (LSAY Research Report No 17). Camberwell, Vic: Australian Council for Educational Research.

Marsh, H. W. (1990) A multidimensional, hierarchical self-concept: Theoretical and empirical justification. Educational Psychology Review, 2, 77-171.

Marsh, H. W. (1992) Content specificity of relations between academic achievement and academic self-concept. Journal of Educational Psychology, 84, 35-42.

Marsh, H. W. (1993) Academic self-concept: Theory measurement and research. In J Suls (Ed.), Psychological Perspectives on the Self (Vol. 4, pp. 59-98). Hillsdale, NJ: Erlbaum.

Marsh, H. W., \& Craven, R. (1997) Academic self-concept: Beyond the dustbowl. In G. Phye (ed.), Handbook of Classroom Assessment: 
Learning, Achievement, and Adjustment. San Diego, CA: Academic Press.

McInerney, D. M., \& Ali, J. (in press, 2006) Multidimensional and hierarchical assessment of school motivation: Cross-cultural validation. Educational Psychology: An International Journal of Experimental Educational Psychology (Volume 26(4) 2006).

McInerney, D. M., Dowson, M. \& Yeung (2005) Facilitating conditions for school motivation: Construct validity and applicability. Educational and Psychological Measurement, 65, 1-21.

McInerney, D. M., Marsh, H. W., \& Yeung, A. S. (2003) Toward a hierarchical model of school motivation. Journal of Applied Measurement, Vol. 4, No. 4, 335-357.

McInerney, D. M., Roche, L., McInerney, V., \& Marsh, H. W. (1997) Cultural perspectives on school motivation: The relevance and application of goal theory. American Educational Research Journal, 34, 207-236.

McInerney, D. M., Yeung, A., \& Dowson, M. (2005) Facilitating conditions for school motivation: Construct validity and applicability. Educational and Psychological Measurement, 65, 10461066.

McInerney, D. M., Yeung, S. Y., \& McInerney, V. (2001) Cross-cultural validation of the Inventory of School Motivation (ISM). Journal of Applied Measurement, 2, 134-152.

Meade, P. (1983) The Educational Experience of Sydney High School Students, Report No.3. Canberra: Australian Government Publishing Service.

Park, C. C. (2000) Learning style preferences of southeast Asian students. Urban Education, 35, 245-268.

Siu, S-F. (1996) Asian American students at risk. A literature review. Report No. 8. Center for Research on the Education of Students Placed at Risk.

Sturman, A. (1997) Social Justice in Education. Australian Education Review No.40._Melbourne: ACER, Victoria.

Sturman, A., Sharpley, B., \& Polesel, J. (1992) Social justice and the curriculum: An investigation into the participation in the curriculum of different groups of Students. (Paper presented at the 1992 AARE National Conference), Deakin University, Geelong.

Suliman, R., \& McInerney, D. M. (in press) Motivational goals and school achievement. Lebanese background students in South Western Sydney. Australian Journal of Education. 
Teese, R., McLean, G., \& Polese, J. (1993) Equity Outcomes. Canberra: Commonwealth Government Printer.

Trueba, H. T., Cheng, L. R. L \& Ima, K. (1993). Myth or reality: Adaptive strategies of Asian Americans in California. Washington, DC: Falmer Press.

Watkins, D., McInerney, D.M. \& Boholst, F. (2003). The reliability and validity of the Inventory of School Motivation: A Filipino investigation. Asian-Pacific Education Researcher, 12, 87-100.

Williams, T., Long, M., Carpenter, P., \& Hayden, M. (1993). Entering Higher Education in the 1980s. Canberra: Australian Government Publishing Service.

Yeung, A.S., \& McInerney, D. M. (2000) Facilitating Conditions for School Motivation. Paper presented at the Annual International Congress for School Effectiveness and Improvement, Hong Kong, Jan 4-8.

Zhenhui, R. (2005) Matching teaching styles with learning styles in East Asian contexts. http://iteslj.org/Techniques/ZhenhuiTeachingStyles.html

\section{ACKNOWLEDGEMENT}

This research was supported by Australian Research Council Grant A00000808. I would also like to acknowledge the assistance of Jinnat Ali in conducting statistical analyses. The paper was originally presented as a keynote address at the Korean Society of Educational Psychology (KSEP) 1st International Conference in Seoul, Korea on December 23, 2005 
